\section{SOI: 1.1/TAS DOI: 10.15863/TAS International Scientific Journal Theoretical \& Applied Science}

p-ISSN: 2308-4944 (print) e-ISSN: 2409-0085 (online)

Year: 2015 Issue: $04 \quad$ Volume: 24

Published: $30.04 .2015 \quad$ http://T-Science.org

SECTION 7. Mechanics and machine construction.

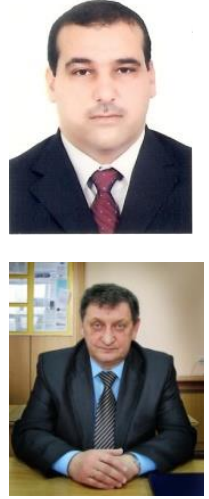

Auday Shaker Hadi

Assistant Lecturer, Ph.D student

University of Technology,

Iraq

aodayshaker@mail.ru

Aleksandr Nikolaevich Litvinov

Doctor of Technical Sciences, Professor

Penza State University,

Russia

aleksletvinov@mail.ru

\title{
STUDY OF LAYER STRUCTURES IN THE DEVICES OF INSTRUMENT ENGINEERING FOR INCREASING SAFETY IN THE PROCESS OF THEIR OPERATIONAL LIFETIME
}

Abstract: For micro-assemblies of the rectangular type representing the heterogeneous structure, the mathematical simulation of strain-stress state for their components was performed at external excess pressure testing. While constructing the mathematical model, the finite element method was used implemented in ANSYS package when one or several multilayer boards are mounted on any plane of the case. The numerical study of micro-assemblies strain-stress state was made and the critical recommendations were given regarding the determination of allowable pressure in the pressure testing taking into consideration the design and engineering particulars of the micro-assembly under design.

Key words: micro-assembly, multilayer boards, excess pressure, pressure testing, strain-stress state, simulation.

Language: English

Citation: Hadi AS, Litvinov AN (2015) STUDY OF LAYER STRUCTURES IN THE DEVICES OF INSTRUMENT ENGINEERING FOR INCREASING SAFETY IN THE PROCESS OF THEIR OPERATIONAL LIFETIME. ISJ Theoretical \& Applied Science 04 (24): 101-107.

Soi: http://s-o-i.org/1.1/TAS*04(24)16 Doi: crossef http://dx.doi.org/10.15863/TAS.2015.04.24.16

At present the problem of safety provision is one of the priority ones as it is closely connected with the design of the modern devices of instrument engineering that represent gadgetry as well as it is connected with the provision of the required performance characteristics $(\mathrm{PCH})$ of such devices [1,p.12;2,p.33].

One of the most important tasks of developing the scientific principles of design and the technology of manufacturing the articles of various applications are the creation of adequate mathematical models describing the response and state of structures and their separate elements in the process of their manufacture, testing, transportation, storage and operation [3,p.8].

The increasing complexity of the structures in the devices of various application leads to the serious economic losses in manufacturing and operation, and in certain cases results in accidents and human losses $[4, p .7]$. The analysis of failures relating to devices and their component parts proves that one of the main causes that reduce their reliability, leads to full or partial failures is the processes going on in the connections of dissimilar materials being under the impact of inner and outer destabilizing factors. In such a case, the major factors are static, dynamic and thermal effects arising at all stages of the operational lifetime of the device: technical operations in the process of manufacturing, testing, storing, transporting and maintaining [3,p.169].

The analysis of design features in the modern engineering devices and their component parts shows that the majority of them are heterogeneous structures combining the materials with different physical and mechanical properties that provides for the required reliability and safety of the device in preset operational modes [5,p.171]. Such devices include the structures of electronic equipment, automation systems and units, communication equipment, meters and sensors of various applications, design elements used in aircraft engineering, shipbuilding industry, rocket engineering as well as the special purpose devices.

In order to study the processes taking place in the structures of such devices under the influence of the external factors, it is necessary to develop the mathematical models and complexes of problemoriented programs for performance of simulation experiments allowing to adequately describe the processes and strain-stress state (SSS) at all stages of 
their operational lifetime. Herewith, it is desirable that these models and program systems possess the formalization properties allowing applying them to the wide range of design elements and structures on the whole. Such approach was used in the works [3,p.169;5,p.3].

In particular, in the work [6,p.5] the mathematical model is suggested allowing studying the strain-stress state of the micro-assemblies cases in the process of their manufacture and operation at the impact of the external excess pressure. The mathematical simulation of the SSS of such cases make it possible to form recommendations on their designing as well as to offer the relatively simple engineering methods of defining the alarm pressure of the technological pressure testing on the integrated circuit cases in the process of their manufacture.

The rapid development of engineering leads to design and technical complexity of devices on condition of increasing their reliability and performance characteristics $(\mathrm{PCH})$ in the difficult operational conditions. That results in the necessity of the further formalization and complication of mathematical models allowing describing adequately the response and state of the elements and structures on the whole at every stage of their operational lifetime[7,p.8;8,p.146].

Let us explore it through the example of microassemblies of rectangular type that have a wide practical application in instrument engineering and special purpose devices. The circuit boards and resistive elements are located on one or several planes inside the micro-assembly providing the required output parameters of micro-assembly. These micro-assemblies are multilayer systems that are exposed to various thermal and mechanical effects during their manufacture and operation. In order to check their impermeability during manufacture, they are undergoing the technological pressure testing with external excess pressure; as a result of such a test the deformation of planes of the case and the circuit boards with resistive elements; that affects the change in their output electric parameters. The value of such pressure is specified in design and technical documentation, very often without preliminary analysis of strain-stress state of micro-assembly and it elements. In a number of cases that results in the appearing of plastic deformations of the case planes, warping distortions of the case as well as cracking of the circuit boards already on the stage of microassembly manufacture. The presence of plastic deformations may lead to failures or violation of micro-assemblies' operating capacity while they are suffering external operational loads[9,p.40].

The SSS simulations of such structures is a quite difficult task, therefore approximate methods are often used for the analysis of their SSS. For example, in the work [6,p.3] the simulation model is based on the SSS analysis of case development drawing. The presence of the circuit board on one or several planes of the case is considered with the introduction of reduced characteristics for the plane that is a multilayer structure. In some cases the mutual influence of case planes for the SSS of the circuit board is not taken into account. It is admissible for limited standard sizes of cases that have small height and rigid side planes. Moreover, the suggested model does not allow studying strainstress state for cases with several multilayer circuit boards located on their planes.

Figure 1 displays the typical structure of hollow micro-assembly of rectangular type with circuit boards that are connected with the base by adhesive joints or soldered seams. Closed rectangular case with dimensions $2 a \times 2 b \times H$ is exposed to the external excess pressure $p$. In the general way, it is considered that the planes of micro-assembly case are made of various materials the mechanical properties of which are characterized by elastic moduli $E_{j}$ and have thicknesses $h_{j}$, where $j=1,2, \ldots, 6$ - number of the plane. To be specific, assume that $j=6$ corresponds to the case cover, $j=1$ - base with the circuit board, $j$ $=2 \ldots 5-$ to the side walls of the case. On the base there located the circuit boards that have thickness $h_{n \kappa}$ and plan dimensions $a_{n \kappa}$ and $b_{n \kappa}$ in the directions $x$ and $z$ accordingly. Here $k=1,2,3 . ., n-$ number of the circuit board, $n$ - number of circuit boards, located on the base. In the most general case, in terms of design the circuit boards may be located on any plane of the case or simultaneously on its several planes. As a rule, the circuit boards are manufactured of the same material, the seam thicknesses $h_{u}$ from the technological point of view are considered the same.

The reference point is located in the center of the base of micro-assembly case. The material of the circuit boards is characterized by the elastic modulus $E_{n}$, Poisson's ratio $v_{n}$, and the material of the seams - shear modulus $G_{u}$ and Poisson's ratio $v_{u}$.

In order to create the adequate threedimensional model allowing analyzing strain-stress state of the elements in the heterogeneous structure of micro-assembly we will use finite element method implemented in ANSYS package [10,p.7;11,p.10]. Such model let to register the mutual influence of case planes, actual dimensions of circuit boards and their locations on the planes as well as the impact of physical and mechanical characteristics of the material used in circuit boards, seams and planes of the case. Besides, the model allows registering the presence of several multilayer circuit boards inside the case including those located on different planes of the case; this may be resulted in dissymmetry in the design of micro-assembly.

As an example we may take some results of numerical simulation of SSS relating to the elements of micro-assembly under the effect of external excess pressure $p$. The case is manufactured of the alloy $29 \mathrm{HK}\left(\mathrm{E}_{\mathrm{j}}=1,4.10^{5} \mathrm{MPa}, v_{\mathrm{j}}=0,3\right.$ at $\left.\mathrm{j}=1,2, . ., 6\right)$, 
circuit boards - of pyroceram $\left(\mathrm{E}_{\mathrm{\Pi}}=9,693.10^{5} \mathrm{MPa}\right.$, $\left.v_{\mathrm{n}}=0,25\right)$, and the properties of seams are characterized by the shear modulus $\mathrm{G}_{\amalg}=\left(10-10^{3}\right)$ $\mathrm{MPa}$. Low values of the shear modulus $\mathrm{G}_{\mathrm{II}}$ conform to the application of 'soft' glues of the sealant type 'Vicsint' y 2-28', and the high values conform to the 'hard' glues of the type BK-9 or to the brazed seams.

a)
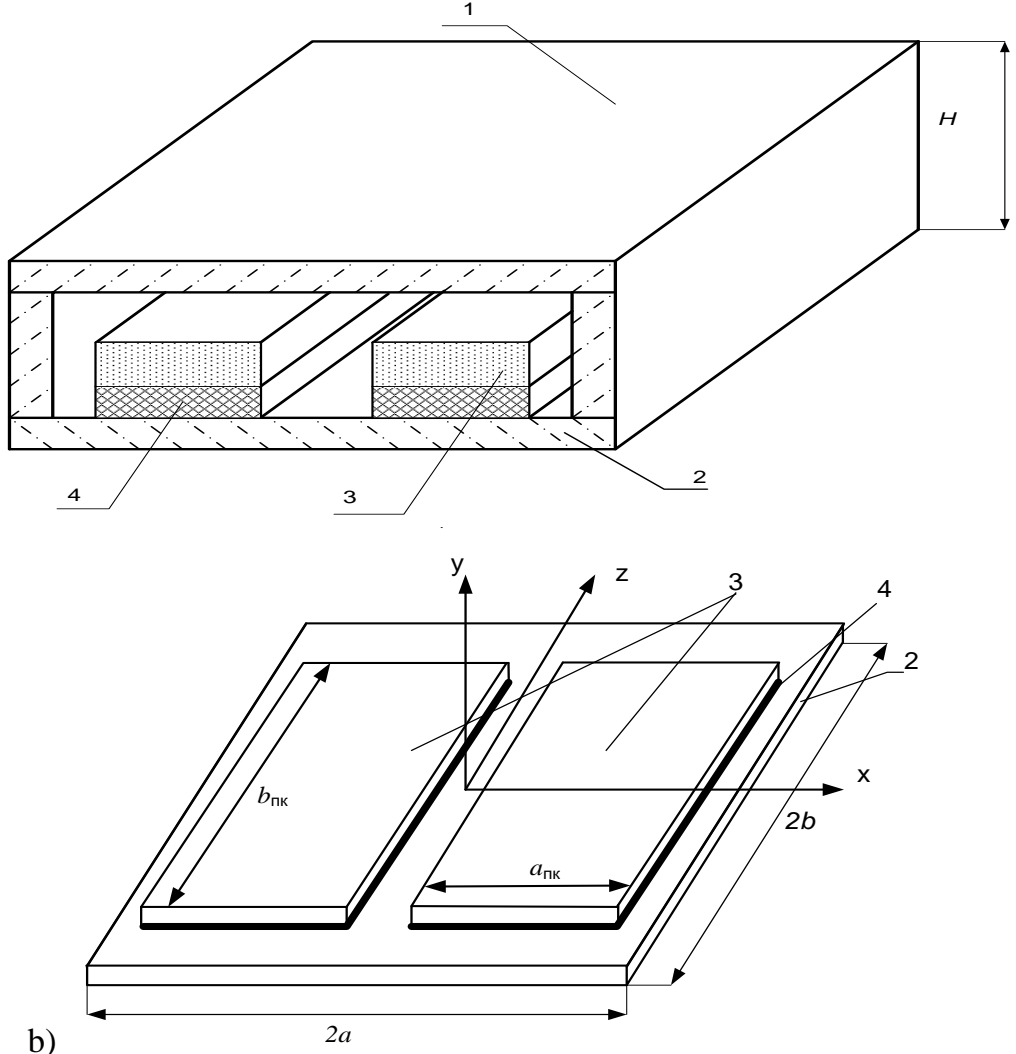

Figure 1 - Micro-assembly :

a) general view : 1 - case; 2 - base; 3 - circuit boards; 4 - seam.

b) base with circuit boards.

The circuit boards are located on the base. Geometrical dimensions of the case are the following: $2 a=2 b=20 \mathrm{~mm} ; h_{j}=0,8 \mathrm{~mm} ; h_{n}=0,6 \mathrm{~mm}$; $\mathrm{H}=5 \mathrm{~mm} ; h_{u}=0,1 \mathrm{~mm}$, the shear modulus of the seam material $G$ varied within the range, conforming to the real micro-assemblies.

As the major output parameters characterizing SSS of the structure under study the deflections $w$ of micro-assembly elements were taken (circuit boards, bases, covers, side planes), equivalent stresses $\sigma_{э к в}$, calculated by Mises criterion, and the intensity of relative strains $\varepsilon_{i}$. The software package also allows printing out shifts, stresses and relative strains by the axes $x, y . z$ (Figure.1) for any element of microassembly.

For analysis convenience and summary of the results regarding the simulation of SSS of the structure elements, the results of the research are represented in relative parameters:

$\bar{\sigma}_{\text {экв }}=\sigma_{\text {экв }} / p$ - nondimensional equivalent stresses;

$\bar{w}=w / p-$ deflection related to the value of the operating pressure (мм/MПа).

Figure 2 and (table 1) display some alternate designs of the base with circuit boards. The circuit boards are located on the base symmetrically about the axes $\mathrm{x}$ and $\mathrm{y}$. 


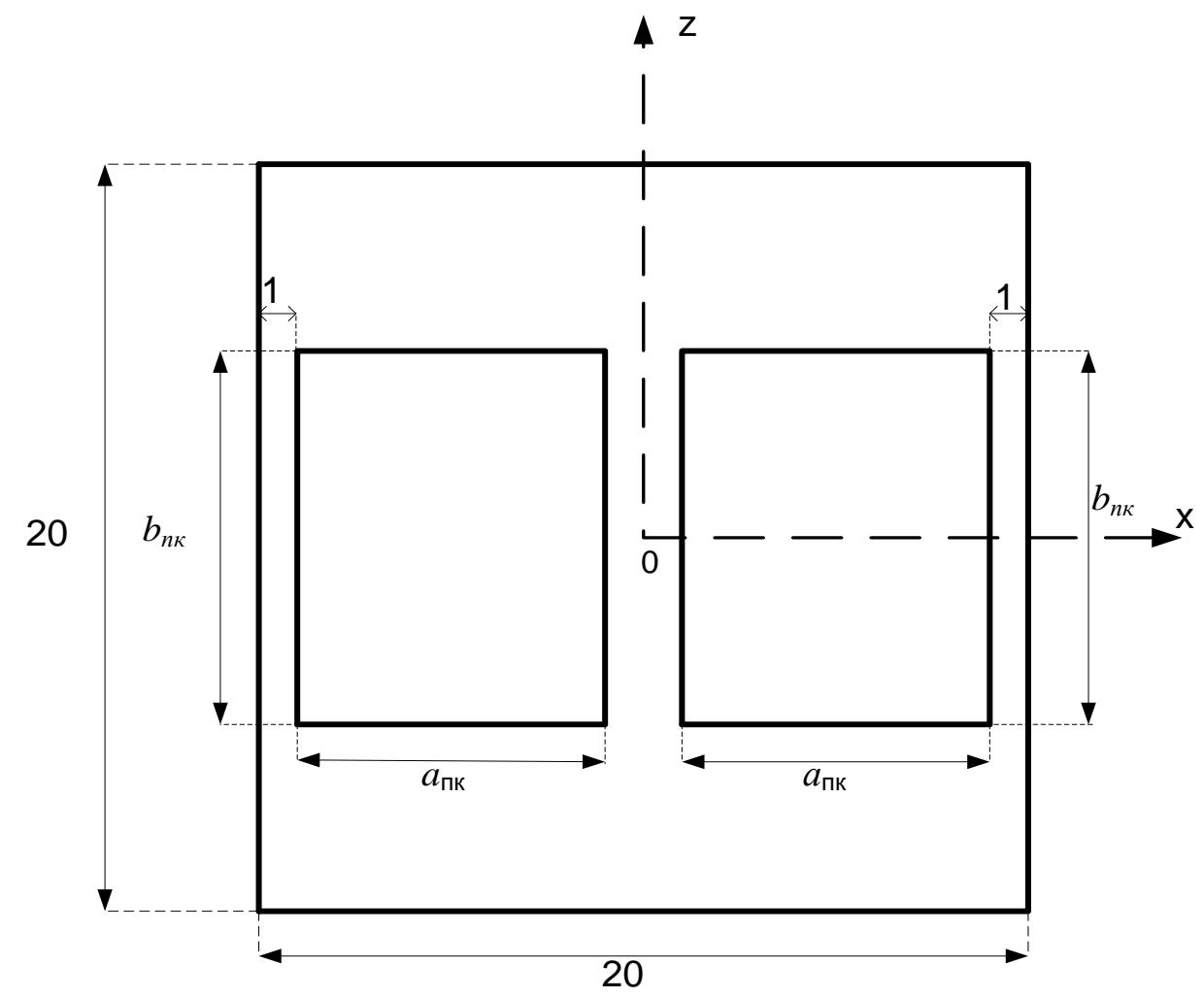

Figure 2 - Location of circuit boards on the base.

The designs of the base with circuit boards.

Table 1

\begin{tabular}{|c|c|c|}
\hline Alternate design & Number of circuit boards & Circuit board dimensions $a_{\text {пा }} \times b_{\text {п }}(\mathrm{MM})$ \\
\hline I & 1 & $16 \times 10$ \\
\hline II & 2 & $8 \times 10$ \\
\hline III & 2 & $5 \times 10$ \\
\hline
\end{tabular}

Figure 3-5 display some results of numerical simulation of SSS of the micro-assemblies' elements relating to the above alternate designs under the impact of the external excess pressure $p$ at $\mathrm{G}=1000$ $\mathrm{MPa}$. Figure. 3 for alternate design III displays the results of SSS simulation in 3-D; they allow visually analyzing SSS of all structure elements.

Figure 4 displays SSS of the base with the circuit board for alternate designs I and II of microasembly. In Figure. 4 the values of stresses $\bar{\sigma}_{\text {экв}}$, indicated on marker in t.A, corresponds to the point located in the center on the outer surface of the micro-assembly base. The rest values of stresses shown on markers conform to the points located in the center of the free (upper) surface of circuit boards.

Figure 5 displays the stress distribution $\bar{\sigma}_{\text {экв }}$ in the base, circuit board and cover of the microassembly for design II. Point A in Figure. 56 still conforms to the center of the base lower surface, and $\mathrm{B}$ - to the central point of the cover.

For a great number of the real micro-assemblies the law $H / a>1$ holds true, i.e. the more loaded are the circuit board and the cover of the micro-assembly.As during the pressure testing the appearance of the plastic deformations are not admissible in the structure elements, then admissible limit value of pressure at the pressure testing $p_{*}$ for microassembly of the type under study should be calculated as the minimum value from $p_{k} u p_{n}$ :

$$
p_{*}=\min \left(p_{k} ; p_{n}\right),
$$

where $p_{k} u p_{n}$ allowed pressures, calculated from the analysis of SSS of cover and circuit board accordingly:

$$
p_{\kappa}=\frac{\sigma_{y}^{k}}{\max \bar{\sigma}_{э \kappa s}^{k}} ; \quad p_{n}=\frac{\sigma_{y}^{n}}{\max \bar{\sigma}_{э \kappa в}^{n}} .
$$

Here $\sigma_{y}^{k}$ and $\sigma_{y}^{n}$ are the proportional elastic limits for the materials of the cover and circuit board; 
$\max \bar{\sigma}_{э к в}^{k} ; \quad \max \bar{\sigma}_{э к в}^{n}$ maximum non-limited equivalent stresses for cover and circuit board accordingly obtained as a result of the analysis of their SSS using this simulation complex .

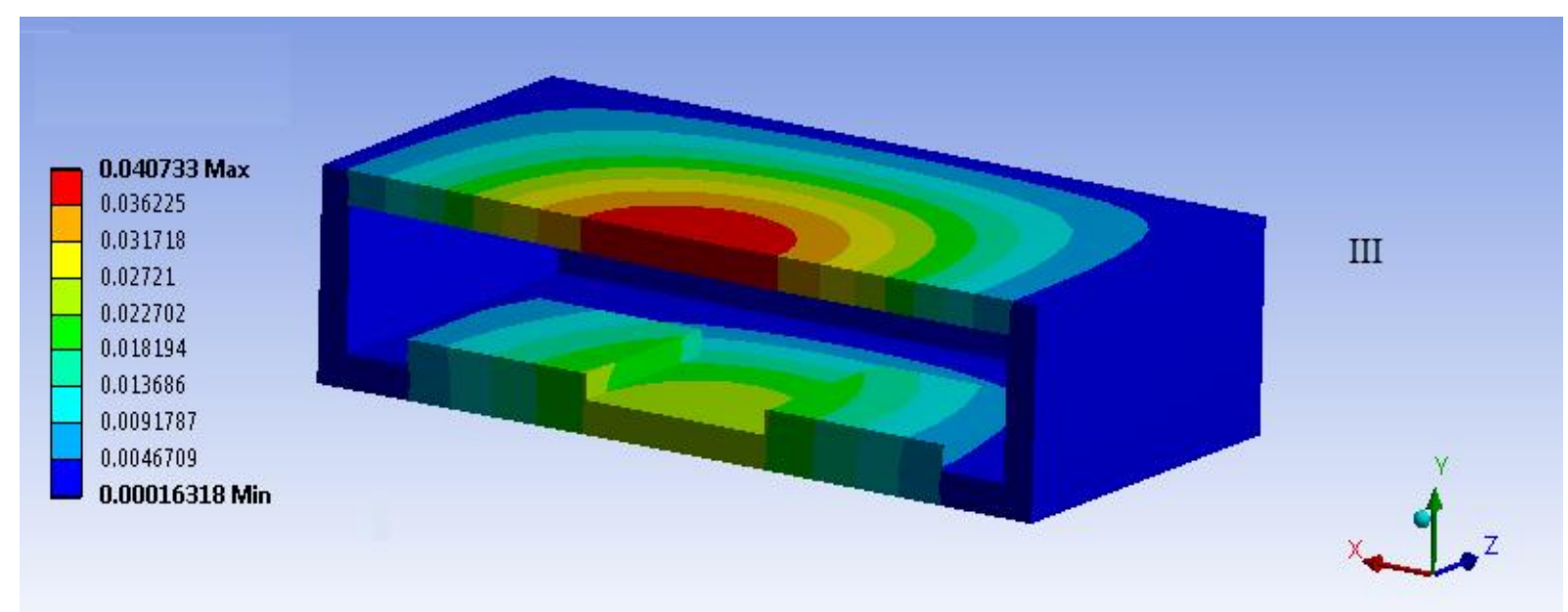

a)
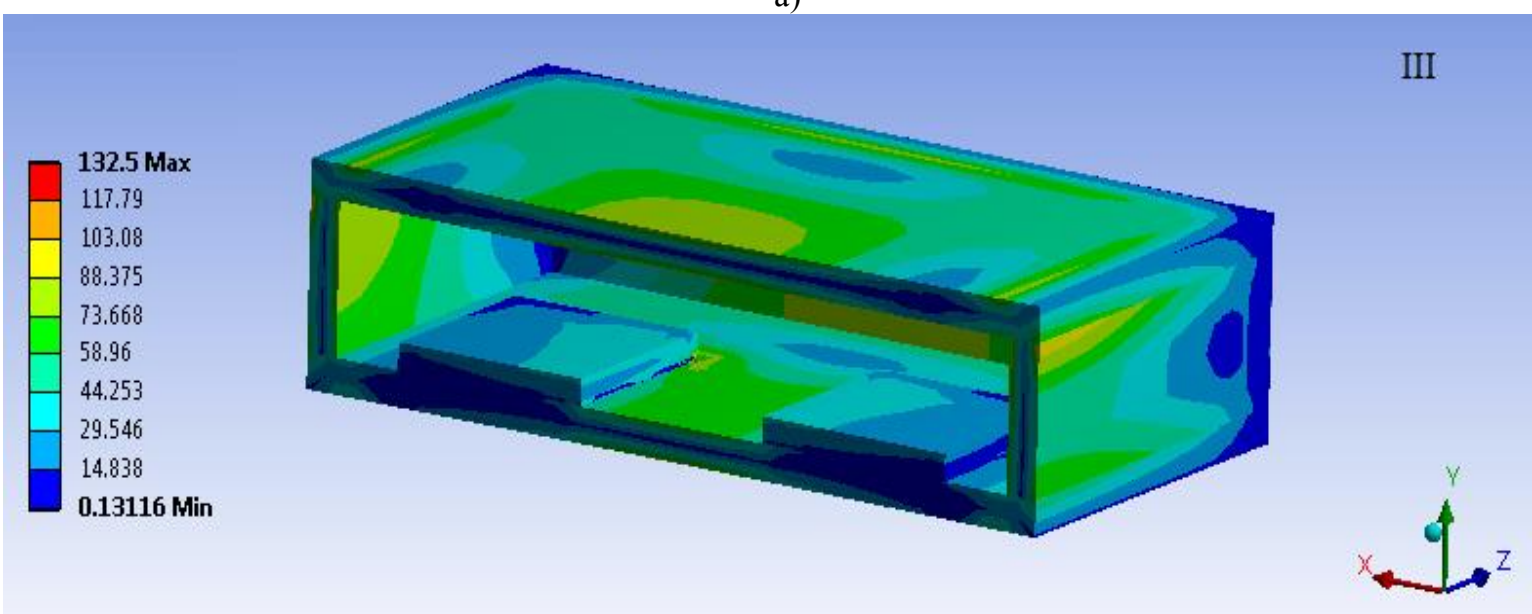

b)

Figure 3 - SSS of micro-assembly:

a) distribution of deflections $\bar{w}$; b) stresses $\bar{\sigma}_{э к в}$.

Simulation of micro-assemblies' SSS of the type under study showed that the increase of adhesive seam thickness leads to the reduction of the equivalent stresses and their more uniform distribution over the surface of the circuit board. Subject to the seam thickness the increase of the shear modulus of the seam material may lead to both increase and the decrease of the stresses in the circuit board. The substantial particular is the fact that the value of stresses on the surface of the circuit board depends on the height of micro-assembly; that can be explained by the mutual influence of the case planes to circuit board SSS that, in turn, influences the output metrological characteristics of microassembly.

The suggested approach is mostly general, it allows creating the adequate model describing SSS of all micro-assembly elements taking into consideration its design features. It enables to optimize the structure according to the set operational impacts as well as to give scientifically grounded instructions to the setting of the mode of the technological operation in regard to the pressure testing while manufacturing of the micro-assembly of the specific size taking into account the locations of one or more circuit boards on its planes. 


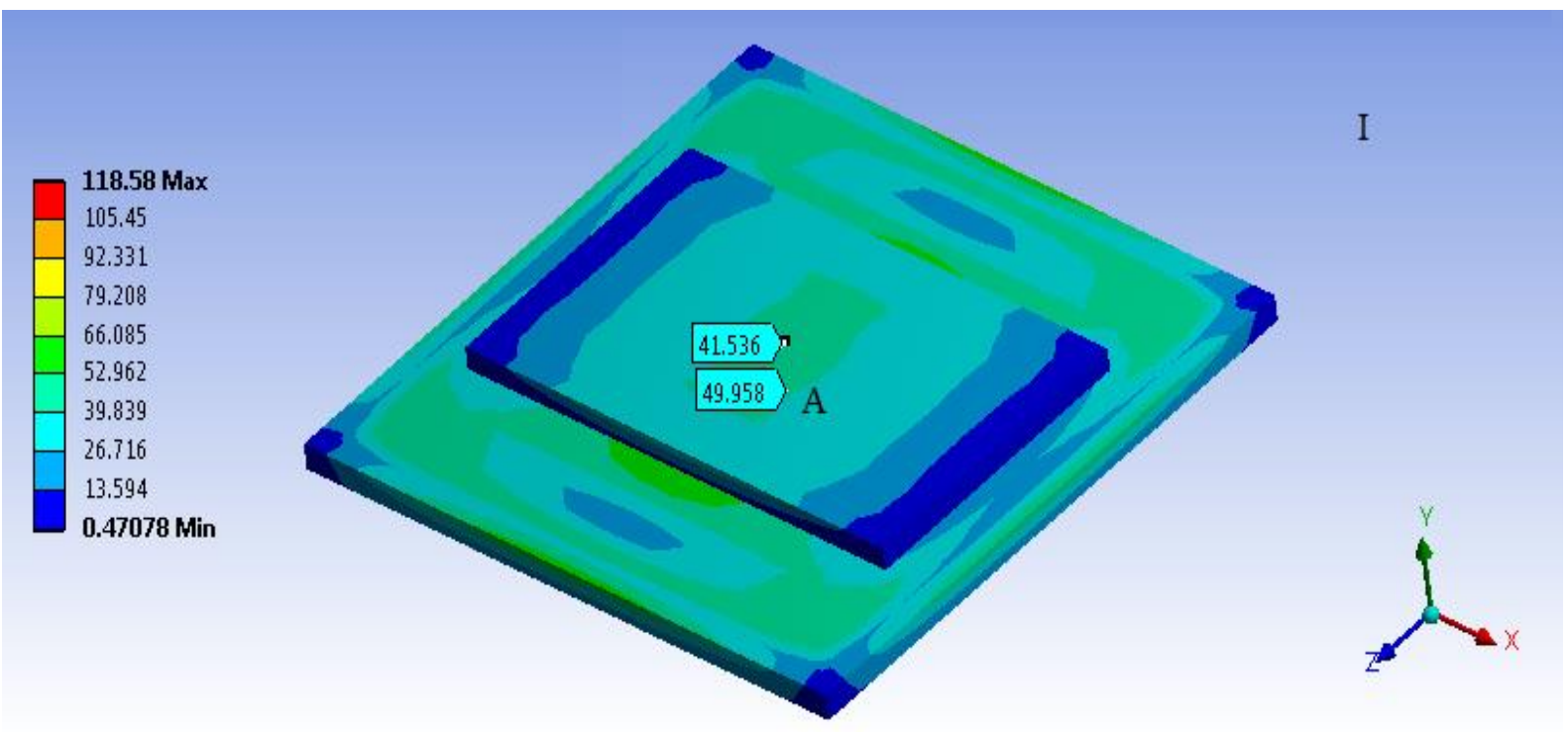

a)

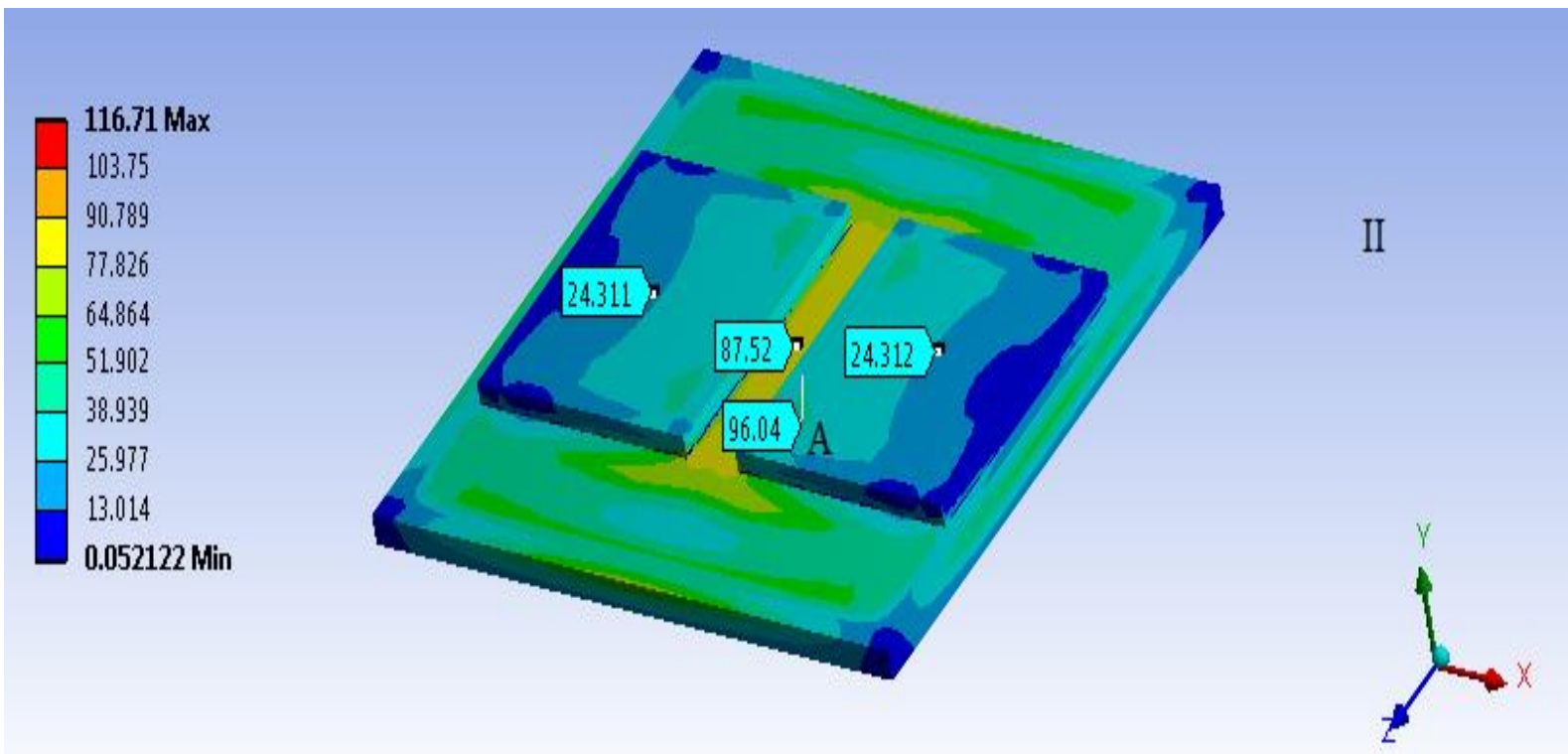

b)

Figure 4 - Distribution $\bar{\sigma}_{э к \varepsilon}$ in the base and circuit boards : a) design I ; b) design II.

Summarizing the performed analysis, we point at the fact that the development and application of the mathematical models and program oriented computer systems allows providing the required reliability and safety of the structures under design on the earlier stages of designing and implementation of the technological processes of manufacture. The selection of simulation mathematical model and its level of complexity (one-dimensional, twodimensional, three-dimensional, registering of heterogeneity and other design features) is determined by the structural features and the required accuracy of the SSS analysis in regard to the structure under design. 


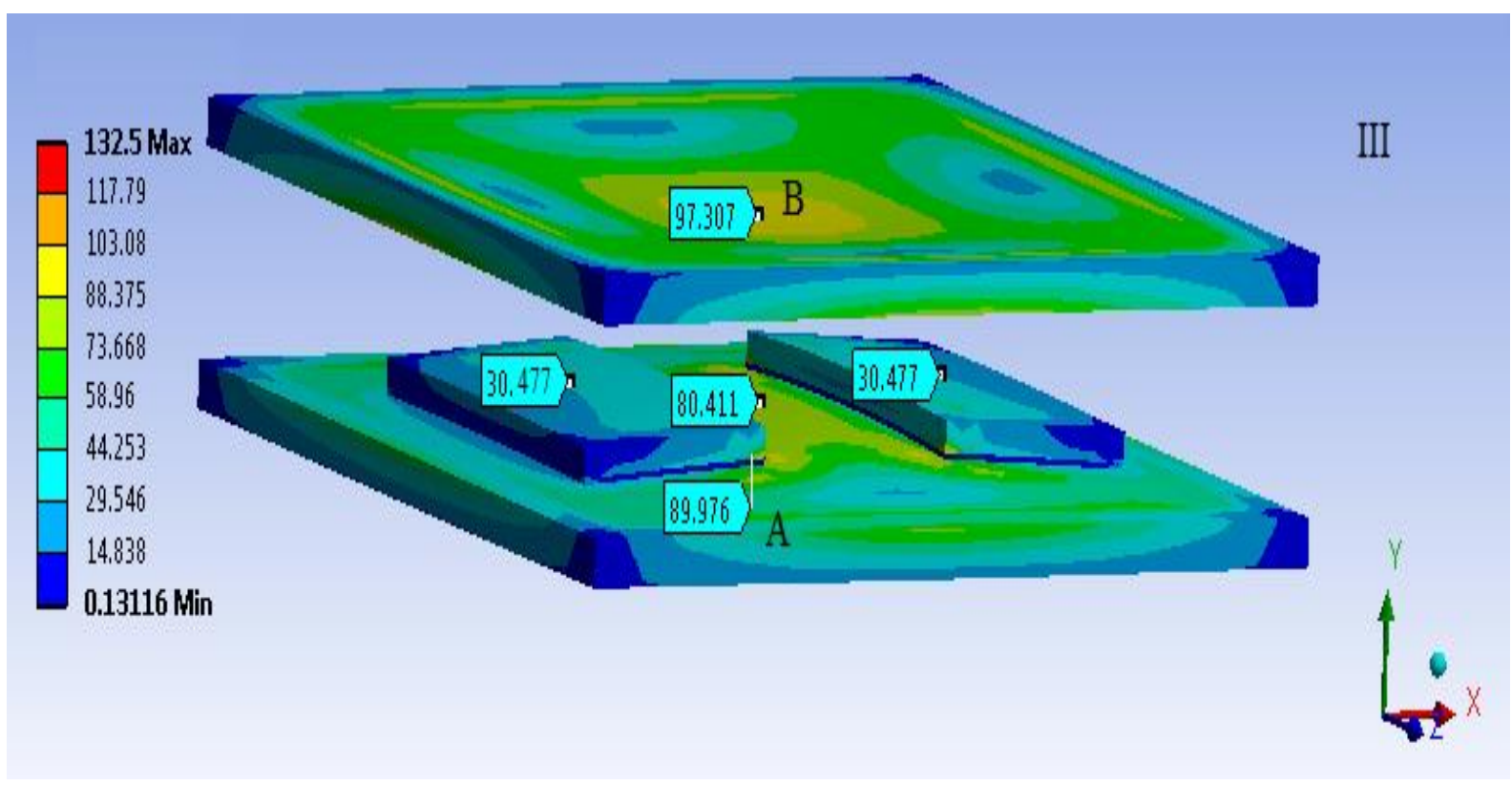

Figure 5 - Distribution $\bar{\sigma}_{э к \varepsilon}$ in the alternate design III.

\section{References:}

1. Severtsev NA, Betskov AV (2009) System Analysis of the Safety Theory -Moscow:MGU Publishers 'Teis', 2009 - pp.452.

2. Litvinov AN, Yurkov NK (2013) Modeling of processes in layered structures to improve the safety of complex technical systems: fundamental problems of system security and stability. Proceedings of the IV mezhdunar.nauchn.konf. Tver.2013. pp.32-35.

3. Litvinov AN, Litvinov MA, Smogunov VV (2009) Application Models of Heterogeneous Structures Mechanics in Devices of Instrument Engineering: Monograph -Penza: PSU Publishers, 2009. - pp.320.

4. Gladkiy SL, Stepanov NA, Yasnitsky LN (2006) Intellectual Simulation of Physical Problems; Under the general editorship of A.N.Yasnitsky - Moscow; Izhevsk: Scientific and Research Center 'Regular and Chaotic Dynamics', Institute of Computer Research, 2006 - pp. 200.

5. Yurkov NK (2012) Technology radioelectronic means: Proc. - Penza ,PSU. - pp.640.

6. Hadi A Sh, Litvinov AN (2013) Simulation of Strain-Stress State in the Micro-Assembly Cases in the Process of Their Manufacture and Operation- Dynamics and Strength (Chapter 1).
Selected Works of Russian National Scientific Conference on Problems of Science and Technologies - Moscow: Russian Academy of Sciences, 2013 - pp. 3-26.

7. Hadi A Sh, Litvinov AN (2014) Modeling of heterogeneous structures to improve safety during the lifecycle of complex technical systems: Reliability and quality of complex systems, 2014, N 3 (7). - pp.8-15.

8. Litvinov AN, Hadi A Sh, Yurkov NK (2014) Modeling of stress-strain state in layered structures with radio-electronic means technological and operational impacts: Proceedings of the universities. Volga region. Engineering science, 2014, N4 (32). - pp. 146157.

9. Lugin AN, Litvinov AN, Ozemsha MM (2001) Thin film resistors sets in thermal influence: journal of electronics. - 2001. - №1. - pp.40-46

10. Kaplun AB, Morozov EM, Olfereva MA (2003) ANSYS in the hands of engineer. Practical guide. Moscow: Editorial URSS, 2003. pp.272.

11. Bass KA (2005) ANSYS: User's Guide. Moscow: DMK Press, 2005.-pp.640. 